\title{
Comparing short versions of the AUDIT in a community-based survey of young people
}

\author{
Anna L Bowring ${ }^{1 *}$, Maelenn Gouillou', Margaret Hellard ${ }^{1,2,3}$ and Paul Dietze ${ }^{1,2}$
}

\begin{abstract}
Background: The 10-item Alcohol Use Disorders Identification Test (AUDIT-10) is commonly used to monitor harmful alcohol consumption among high-risk groups, including young people. However, time and space constraints have generated interest for shortened versions. Commonly used variations are the AUDIT-C (three questions) and the Fast Alcohol Screening Test (FAST) (four questions), but their utility in screening young people in non-clinical settings has received little attention.

Methods: We examined the performance of established and novel shortened versions of the AUDIT in relation to the full AUDIT-10 in a community-based survey of young people (16-29 years) attending a music festival in Melbourne, Australia (January 2010).

Among those reporting drinking alcohol in the previous 12 months, the following statistics were systematically assessed for all possible combinations of three or four AUDIT items and established AUDIT variations: Cronbach's alpha (internal consistency), variance explained $\left(R^{2}\right)$ and Pearson's correlation coefficient (concurrent validity). For our purposes, novel shortened AUDIT versions considered were required to represent all three AUDIT domains and include item 9 on alcohol-related injury.

Results: We recruited 640 participants (68\% female) reporting drinking in the previous 12 months. Median AUDIT-10 score was 10 in males and 9 in females, and 127 (20\%) were classified as having at least high-level alcohol problems according to WHO classification.

The FAST scored consistently high across statistical measures; it explained $85.6 \%$ of variance in AUDIT-10, correlation with AUDIT-10 was 0.92, and Cronbach's alpha was 0.66. A number of novel four-item AUDIT variations scored similarly high. Comparatively, the AUDIT-C scored substantially lower on all measures except internal consistency.

Conclusions: Numerous abbreviated variations of the AUDIT may be a suitable alternative to the AUDIT-10 for classifying high-level alcohol problems in a community-based population of young Australians. Four-item AUDIT variations scored more consistently high across all evaluated statistics compared to three-item combinations. Novel AUDIT versions may be more effective than many established shortened versions as an alternative screening tool to the AUDIT-10 to measure hazardous or harmful alcohol consumption in this population.
\end{abstract}

Keywords: Alcohol screening, Alcohol use disorders identification test, AUDIT, Alcohol consumption, Young adult, Adolescents

\footnotetext{
* Correspondence: annab@burnet.edu.au

${ }^{1}$ Centre for Population Health, Burnet Institute, 85 Commercial Rd,

Melbourne, VIC 3004, Australia

Full list of author information is available at the end of the article
} 


\section{Background}

Risky alcohol consumption is common among Australian young people and associated with elevated incidence of accidents, physical injury and other short-term harm, as well as contributing to long-term health conditions and alcohol dependence [1-4]. In epidemiological research, monitoring alcohol consumption and related harm is important to identify high-risk groups, risk behaviours, and trends in alcohol use in order to inform, target and evaluate harm reduction strategies.

The Alcohol Use Disorders Identification Test (AUDIT) was developed by the World Health Organisation (WHO) as a simple clinical screening tool to detect hazardous and harmful alcohol use and facilitate early intervention in primary care [5]. The AUDIT comprises ten questions covering the domains of alcohol consumption (questions 1-3), alcohol dependence (Q4-6), and harms (Q7-10) and is scored out of 40 [6]. Although the AUDIT was developed as a tool for use in clinical practice, it has been used more broadly for web-based screening and epidemiological research [7-9]. The AUDIT has also been adapted into shortened versions containing subsets of AUDIT items for use in settings subject to time constraints [9]. The most common shortened versions are the AUDIT-C [10], AUDIT-3[11], AUDIT-4 [12], and the Fast Alcohol Screening Test (FAST) [13]). Previous research suggests that shortened versions may be sufficient proxies for the full AUDIT (AUDIT-10), but evaluations of both the AUDIT-10 and shortened AUDIT versions are generally limited to clinical [10-12,14-18] or adult general population samples $[7,8,19-21]$, with the exception of a number of studies of the AUDIT-10 in college students [22-25]. Although some of these studies have reported results among young adults $[19,26]$, there is a need for further research to determine the performance of shortened AUDIT versions in high-risk populations such as young people aged less than 18 years.

We have been conducting alcohol, other drug and sexual risk behaviour surveillance of young people attending a music festival in Melbourne, Australia since 2005 $[27,28]$. While the AUDIT-10 is a candidate instrument to classify alcohol consumption and risk, space constraints on our questionnaire make it difficult to conduct the full AUDIT-10; a shortened version that captures important information across the consumption, dependence and harms domains suited to our recruitment setting is required; to our knowledge, no such instrument exists. In this study we assess how established and novel shortened versions of the AUDIT perform in relation to the full AUDIT-10 in a community-based sample of young people attending a music festival. Our results will inform our subsequent community-based surveys and be useful for others conducting research with young nonclinical populations.

\section{Methods}

\section{Setting and recruitment}

Individuals aged 16-29 years were recruited at the Melbourne Big Day Out music festival in January 2010 as part of an ongoing behavioural surveillance system, which has been described in detail elsewhere [27-29]. The oneday music festival had over 50,000 attendees in 2010 [30], but the proportion of attendees aged 16-29 is unknown. In brief, approximately 20 trained researchers recruited participants from in and around a market stall within the festival and explained the survey and involvement. Participants were asked to self-complete a consent form and two-page questionnaire. We provided participants with educational materials on alcohol and drug use, sexual health, and mental health, and condoms; participants were also offered bottled water, lollipops, and entry to a prize draw as an incentive for participation.

\section{Questionnaire}

Each year study participants are asked a core set of questions including demographics, sexual health and behaviour, alcohol consumption and other drug use $[27,28,31]$. In 2010 we used the AUDIT-10 to assess alcohol consumption and risk.

\section{Analysis}

Data were entered into a Microsoft Access database and statistical analysis was conducted in Stata version 11 [32]. The analysis excluded participants who reported never drinking in the past 12 months $(n=34)$ or who had missing responses to any AUDIT items $(n=17)$. The AUDIT-10 was scored from 1 to 40 [6]. Additionally, established shortened versions of the AUDIT were scored (Table 1). AUDIT-10 scores were further classified into hazardous drinking $(\geq 8)$, high-level of alcohol problems $(\geq 16)$, and possible alcohol dependence $(\geq 20)$ categories according to WHO recommended thresholds [6]. Comparisons of these classifications by sex were assessed using the $X^{2}$ test of proportions.

All possible combinations of three- and four-item AUDIT scales were evaluated. For our purposes the final shortened AUDIT versions considered were required to: represent all three AUDIT domains (alcohol consumption, C; alcohol dependence, D; and harmful alcohol use, $\mathrm{H}$ ) and include item 9 on alcohol-related injury, or be an established AUDIT variation with maximum four items (AUDIT-3, AUDIT-C, FAST, AUDIT-4). Item 9 was a key inclusion because of the focus on alcohol-related injury among young people in Australia [33]. Typically, FAST is a four-item abbreviation of the AUDIT but applies different drinking levels for males and females in item 3 (eight and six, respectively) [13]; however, the FAST we used included the standard AUDIT designation of six or more drinks for both sexes. 
Table 1 Explained variance of individual AUDIT items to AUDIT-10 score and item inclusion in common established shortened AUDIT versions

\begin{tabular}{|c|c|c|c|c|c|c|c|c|}
\hline \multirow[b]{2}{*}{$\begin{array}{l}\text { Item } \\
\text { no. }\end{array}$} & \multirow[b]{2}{*}{ The AUDIT questions } & \multirow[b]{2}{*}{$\begin{array}{l}\text { AUDIT } \\
\text { Domain }\end{array}$} & \multirow[b]{2}{*}{$\begin{array}{l}\text { Explained variance } \\
\text { of total AUDIT-10 } \\
\text { score }\left(R^{2}\right)\end{array}$} & \multicolumn{5}{|c|}{ Established AUDIT Variations } \\
\hline & & & & $\begin{array}{l}\text { AUDIT- } \\
10\end{array}$ & $\begin{array}{l}\text { AUDIT- } \\
\text { C }\end{array}$ & $\begin{array}{l}\text { AUDIT- } \\
3\end{array}$ & FAST & $\begin{array}{l}\text { AUDIT- } \\
4\end{array}$ \\
\hline 1 & How often do you have a drink containing alcohol? & C & $30.7 \%$ & - & - & & & - \\
\hline 2 & $\begin{array}{l}\text { How many drinks containing alcohol do you have on a } \\
\text { typical day when you are drinking? }\end{array}$ & C & $30.0 \%$ & - & - & & & - \\
\hline 3 & How often do you have 6 or more drinks on one occasion? & C & $47.1 \%$ & - & - & - & - & - \\
\hline 4 & $\begin{array}{l}\text { How often during the last year have you found that you } \\
\text { were not able to stop drinking once you had started? }\end{array}$ & $\mathrm{D}$ & $48.8 \%$ & - & & & & \\
\hline 5 & $\begin{array}{l}\text { How often during the last year have you failed to do what } \\
\text { was normally expected of you because of alcohol? }\end{array}$ & $\mathrm{D}$ & $44.6 \%$ & - & & & - & \\
\hline 6 & $\begin{array}{l}\text { How often during the last year have you needed a first drink } \\
\text { in the morning to get yourself going after a heavy } \\
\text { drinking session? }\end{array}$ & $\mathrm{D}$ & $31.3 \%$ & - & & & & \\
\hline 7 & $\begin{array}{l}\text { How often during the last year have you had a feeling of } \\
\text { guilt or remorse after drinking? }\end{array}$ & $\mathrm{H}$ & $39.6 \%$ & - & & & & \\
\hline 8 & $\begin{array}{l}\text { How often during the last year have you been unable to } \\
\text { remember what happened the night before because of } \\
\text { your drinking? }\end{array}$ & $\mathrm{H}$ & $45.5 \%$ & - & & & - & \\
\hline 9 & $\begin{array}{l}\text { Have you or someone else been injured because of your } \\
\text { drinking? }\end{array}$ & $\mathrm{H}$ & $28.9 \%$ & - & & & & \\
\hline \multirow[t]{2}{*}{10} & Has a relative, friend, doctor, or other health care worker & $\mathrm{H}$ & $34.5 \%$ & - & & & - & - \\
\hline & & & Score range: & $1-40$ & $1-12$ & $0-4$ & $0-16$ & $1-16$ \\
\hline
\end{tabular}

${ }^{1}$ AUDIT domains are: $C$, alcohol consumption; $D$, alcohol dependence; $H$, harmful alcohol use.

Three statistics were systematically assessed for all possible combinations of three or four AUDIT items and established AUDIT variations: (1) Cronbach's alpha was calculated to measure internal consistency of each AUDIT version, with a value of 0.7 or greater taken to indicate satisfactory reliability [5]; (2) $\mathrm{R}^{2}$ statistics from linear regression between individual items or novel combination and the total AUDIT score were calculated to measure the total variance explained in the overall AUDIT-10 score by each individual item and novel combination of items; and (3) Pearson's correlation coefficients were calculated to examine the concurrent validity between each shortened AUDIT version and the AUDIT-10 scale. All shortened AUDIT versions meeting our criteria were ranked from highest to lowest for each of the three statistics, and reranked based on the sum of all ranks.

\section{Ethics}

Ethical approval was granted by the Alfred Hospital Human Research Ethics Committee.

\section{Results}

\section{Demographic profile}

Analysis was based on 640 participants completing the AUDIT-10, 68\% of whom were female. Participants' median age was 19.9 years. The majority were Australian-born (93\%), lived in a major-city (71\%) [34], and lived with parents $(64 \%)$. Half had completed or were in the process of completing post-high school education. One-fifth of participants reported having used drugs other than alcohol in the month prior to the survey. The median AUDIT-10 score was 10 (interquartile-range [IQR] 7-16) among males and 9 (IQR 6-14) among females. Using WHO recommended threshold scores [6], 417 (65\% of the total sample) were classified as at least hazardous drinkers (score $\geq 8$ ), 127 (20\% of the total sample) as having at least high-level alcohol problems (score $\geq 16$ ), and 65 ( $10 \%$ of the total sample) as possibly alcohol dependent (score $\geq 20$ ); these classifications did not differ by sex $(\mathrm{p}=0.12)$.

Table 1 shows the individual items of the AUDIT-10 and the items included in common AUDIT variations, along with the variance explained by each item in relation to the total AUDIT-10 score observed in the sample.

In total 330 three- or four- item combinations were possible, and $51(15 \%)$ combinations met the criteria of containing item 9 and representing three domains. An additional four established AUDIT variations were considered, thus eligible AUDIT variations were ranked from 1 to 55 according to performance across the three calculated statistics. Table 2 shows the top ten performing novel 


\begin{tabular}{|c|c|c|c|c|c|}
\hline $\begin{array}{l}\text { Overall } \\
\text { rank }\end{array}$ & $\begin{array}{l}\text { Selected novel \& established } \\
\text { combinations }\end{array}$ & $\begin{array}{c}\text { AUDIT } \\
\text { domains }^{1}\end{array}$ & $\begin{array}{l}\text { Explained variance of total } \\
\text { AUDIT-10 score }\left(R^{2}\right)\end{array}$ & $\begin{array}{l}\text { Cronbach's } \\
\text { alpha }\end{array}$ & $\begin{array}{c}\text { Pearson's } \\
\text { correlation (r) } \\
\end{array}$ \\
\hline 1 & $\operatorname{FAST}(3,5,8 \& 10)$ & $C, D, H$ & 0.86 & 0.66 & 0.92 \\
\hline 2 & $3,4,8 \& 9$ & $C, D, H$ & 0.87 & 0.62 & 0.92 \\
\hline 3 & $3,4,5 \& 9$ & $C, D, H$ & 0.87 & 0.61 & 0.92 \\
\hline 4 & $3,5,8 \& 9$ & $C, D, H$ & 0.87 & 0.60 & 0.92 \\
\hline 5 & $3,4,7 \& 9$ & $C, D, H$ & 0.87 & 0.59 & 0.92 \\
\hline 6 & $3,4,9 \& 10$ & $C, D, H$ & 0.86 & 0.59 & 0.91 \\
\hline 7 & $3,5,7,9$ & $C, D, H$ & 0.86 & 0.59 & 0.91 \\
\hline 8 & $3,5,9 \& 10$ & $C, D, H$ & 0.86 & 0.58 & 0.90 \\
\hline 9.5 & $3,4,6 \& 9$ & $C, D, H$ & 0.86 & 0.55 & 0.92 \\
\hline 9.5 & $2,3,4 \& 9$ & $C, D, H$ & 0.83 & 0.60 & 0.89 \\
\hline 34 & $3,4 \& 9$ & $C, D, H$ & 0.81 & 0.48 & 0.88 \\
\hline 40 & $3,5 \& 9$ & $C, D, H$ & 0.80 & 0.46 & 0.87 \\
\hline 45 & AUDIT-4 (1, 2, 3 \& 10) & $\mathrm{C}, \mathrm{H}$ & 0.70 & 0.67 & 0.83 \\
\hline 47 & AUDIT-C (1, 2 \& 3) & C & 0.56 & 0.70 & 0.74 \\
\hline 48 & $3,6 \& 9$ & $C, D, H$ & 0.78 & 0.37 & 0.85 \\
\hline 49 & $1,4 \& 9$ & $C, D, H$ & 0.75 & 0.43 & 0.85 \\
\hline 50 & $2,4 \& 9$ & $C, D, H$ & 0.75 & 0.46 & 0.85 \\
\hline 51 & $1,5 \& 9$ & $C, D, H$ & 0.74 & 0.40 & 0.84 \\
\hline 52 & $2,5 \& 9$ & $C, D, H$ & 0.73 & 0.44 & 0.83 \\
\hline 53 & $2,6 \& 9$ & $C, D, H$ & 0.70 & 0.34 & 0.81 \\
\hline 54 & $1,6 \& 9$ & $C, D, H$ & 0.68 & 0.33 & 0.80 \\
\hline 55 & AUDIT-3 (3) & C & 0.47 & NA & 0.69 \\
\hline
\end{tabular}

NA- not applicable.

${ }^{1}$ AUDIT domains are: $C$, alcohol consumption; $D$, alcohol dependence; $H$, harmful alcohol use.

combinations of both three and four AUDIT items that meet the study criteria, in addition to the established AUDIT variations.

\section{Cronbach's alpha (internal consistency)}

The internal consistency of the AUDIT-10 in this sample was 0.80 . The highest internal consistency of the threeitem combinations was obtained with the AUDIT-C (0.70), followed by the novel combination of items 3,4 , and 9 (0.48) (Table 2). The highest internal consistency of the four-item combinations was obtained with the two established variations AUDIT-4 (0.67) and the FAST (0.66), followed by combination $3,4,8$ and $9(0.62)$.

\section{Variance explained}

Of all three-item combinations, the combination of items 3, 4 and 9 explained the most variance $(80.1 \%)$ in AUDIT-10 score while AUDIT-C explained only 55.8\% of variance. Of the four-item combinations, the combination 3, 4, 7, and 9 explained the most variance (87.4\%) in AUDIT-10, with numerous other four-item combinations explaining greater than $86 \%$ variance (Table 2 ). In comparison, AUDIT-4 explained $70.0 \%$ and the FAST explained $85.6 \%$ of variance in AUDIT-10 score.

\section{Pearson's correlation coefficient (concurrent validity)}

Correlation with the AUDIT-10 was highest with the three-item combination 3, 4 and 9 (0.88), but four other combinations demonstrated correlation of at least 0.85 . In contrast, the correlation between AUDIT-C and AUDIT-10 was lower. Six variations of four-item combinations, including the FAST, had a correlation coefficient of 0.92 with AUDIT-10. In contrast, correlation between AUDIT-4 and AUDIT-10 was lower with a coefficient of only 0.83 .

\section{Discussion}

This study highlights how shortened versions of the AUDIT, using just a few items, can capture much of the information available from the full AUDIT scale, thus suggesting they may be as effective a screening tool to measure hazardous or harmful alcohol consumption. A number of shortened versions of the AUDIT performed well in relation to the AUDIT-10 by means of internal 
consistency, variance explained, and concurrent validity. Although some three-item combinations scored highest for individual measures, four-item combinations scored more consistently high across all statistical tests. Novel AUDIT versions may be more effective than many established shortened versions as an alternative screening tool to the AUDIT-10 to measure hazardous or harmful alcohol consumption in community-based populations of young Australians.

While AUDIT-C was the only AUDIT version under our study criteria which met the Cronbach's alpha cutoff of at least 0.7 for research purposes [5,35], it did not perform well by other measures. The AUDIT-C exists in a single AUDIT domain based on consumption patterns, and thus items are more likely to correlate with each other, leading to a higher Cronbach's alpha [36]. In contrast, the alternative novel versions crossed three domains that measured different types of alcohol misuse, as prioritised in the study protocol, so lower internal consistency may be reasonable.

Using just three of ten AUDIT questions was sufficient to explain over $80 \%$ of total variance in the AUDIT- 10 score, with any additional items increasing this figure slightly. In general, correlation with AUDIT-10 was high, which may be due to the shortened AUDIT versions being subsets of the AUDIT-10 and not independent measures, as well as our study criteria for only considering novel combinations which represented all three AUDIT domains. In contrast, the AUDIT-C, which only covers one domain, explained considerably less variance and had lower correlation to the AUDIT-10 than novel combinations, which was also observed in a previous computerised survey of young people [37].

Our results suggest that numerous variations of the AUDIT scale may be a suitable alternative to the AUDIT10 for classifying harmful and hazardous drinking in this sample of young people. When considering performance of AUDIT variations across all statistical measures, the FAST scored highest overall. However, the FAST does not include item 9 on alcohol-related injury, which was prioritised due to its significance to young people [33]. Nonetheless, there are advantages to using the FAST, given it has been validated in other settings, albeit primarily emergency departments $[13,17,21]$. After FAST, the two top-performing variations were similar: $3,4,8$ and 9 or $3,4,5$, and 9 . There is no sound basis for choosing one of these combinations over the other in this sample population, although item 8 on memory loss has been shown to be a useful measure of harm and predictor of future alcohol-related injury in young people [37,38].

A number of limitations to this study and interpretation should be considered. The survey did not include a gold-standard or comparative clinical diagnosis of harmful/hazardous alcohol use or alcohol-related problems, such as DSM-IV, meaning we were unable to assess predictive validity. Subsequently, novel AUDIT variations were compared to the AUDIT-10, which itself has not been validated in this particular population, and some prior research has reported that the AUDIT is less reliable in the general population compared to clinical settings [8]. As such, we are only able to determine the performance of the shortened AUDIT variations in comparison to the full AUDIT, rather than as a predictor of harmful drinking per se; agreement does not infer accuracy of either the shortened versions or AUDIT-10 as a predictor of hazardous drinking or high-level drinking problems. Furthermore, the shortened AUDIT models are not independent of the AUDIT-10, and thus undermine the assumption of independence for assessing linear regression (variance explained). While this method has been used in previous related studies, it should still be interpreted with caution (e.g. [37]). A modified version of the FAST that was not gender-specific was used and may have overstated the performance of FAST in comparison to AUDIT-10.

This study population is based on a convenience sample and is not intended to be representative of all young Australians. In addition, due to the nature of the recruitment setting, we were unable to assess a response rate for participation. Prior surveys have demonstrated that participants recruited at the Melbourne Big Day Out music festival are more likely to engage in alcohol-, drug-, and sex-related risk behaviours than other young Australians $[39,40]$. While the high-risk nature of this sub-population makes them an important group for testing the performance of AUDIT variations, results may differ in other populations. Further research is needed to confirm findings in broader and more representative samples.

\section{Conclusion}

Among a sample of young people commonly reporting risky alcohol consumption, we identified a number of novel three and four-item AUDIT variations, as well as the established FAST scale, which were suitable proxies of the AUDIT-10. Although it is difficult to ascertain a single standout shortened AUDIT variation in this population, numerous variations performed better than the more widely used AUDIT-C according to multiple criteria. Four-item combinations scored more consistently high across evaluated statistical measures and are the preferred compromise for maximising the indication of alcohol misuse while ensuring a short and simple measure of hazardous drinking in a community-based sample of young people.

\section{Competing interests}

The authors report no competing interests relating to this manuscript. 


\section{Authors' contributions}

The following co-authors have contributed to the work: $A B$ in data collection, data analysis, manuscript preparation and manuscript review; MG in data analysis and manuscript review; $\mathrm{MH}$ in study design, manuscript preparation and manuscript review; and PD in study design, data analysis, manuscript preparation and manuscript review. All authors read and approved the final manuscript.

\section{Acknowledgements}

$\mathrm{MH}$ and PD received people support funding from the NH\&MRC, and PD is the recipient of an ARC Future Fellowship. The 2010 survey was funded internally by the Burnet Institute. The authors gratefully acknowledge the contribution to this work of the Victorian Operational Infrastructure Support Program. The authors thank Bianca Fiebeger for allowing us to recruit at the Big Day Out music festival; the trained recruiters who explained the survey to study participants and collected written consent and data; and the study participants. Showbag contents were donated by the Victorian Department of Justice, Marie Stopes International, Youth Projects, Headspace, Department of Health and Ageing, and Cadbury Schweppes.

\section{Author details}

${ }^{1}$ Centre for Population Health, Burnet Institute, 85 Commercial Rd, Melbourne, VIC 3004, Australia. ${ }^{2}$ Department of Epidemiology and Preventive Medicine, Monash University, Melbourne, VIC, Australia. ${ }^{3}$ The Nossal Institute for Global Health, The University of Melbourne, Melbourne, VIC, Australia.

\section{Received: 12 September 2012 Accepted: 27 March 2013}

Published: 4 April 2013

\section{References}

1. Livingston $M$, Room R: Variations by age and sex in alcohol-related problematic behaviour per drinking volume and heavier drinking occasion. Drug Alcohol Depen 2009, 101(3):169-175.

2. NHMRC: Australian Guidelines to Reduce Health Risks from Drinking Alcohol. Canberra: Department of Health and Ageing; 2009.

3. Bonomo YA, Bowes G, Coffey C, Carlin JB, Patton GC: Teenage drinking and the onset of alcohol dependence: a cohort study over seven years. Addiction 2004, 99:1520-1528.

4. Meyers P: Victorian Youth Alcohol and Drug Survey, 2009. Final Report Commissioned by the Victorian Drug and Alcohol Prevention Council for the Department of Health. Melbourne: Social Research Centre; 2010.

5. Saunders JB, Aasland OG, Babor TF, De La Fuente JR, Grant M: Development of the Alcohol Use Disorders Identification Test (AUDIT): WHO Collaborative Project on Early Detection of Persons with Harmful Alcohol Consumption-II. Blackwell Publishing Ltd 1993, 88:791-804.

6. Babor T, Higgins-Biddle J, Saunders J, Monteiro M: The Alcohol Use Disorders Identification Test: Guidelines for use in primary care, 2nd edn. Geneva: World Health Organization, Department of Mental Health and Substance Dependence; 2001

7. Aalto M, Alho H, Halme JT, Seppa K: AUDIT and its abbreviated versions in detecting heavy and binge drinking in a general population survey. Drug Alcohol Depend 2009, 103(1-2):25-29.

8. Rumpf H, Hapke U, Meyer C, John U: Screening for alcohol use disorders and at-risk drinking in the general population: psychometric performance of three questionnaires. Alcohol Alcohol 2002, 37(3):261.

9. Reinert DF, Allen JP: The alcohol use disorders identification test: an update of research findings. Alcohol Clin Exp Re 2007, 31(2):185-199.

10. Kriston L, Hölzel L, Weiser A-K, Berner MM, Härter M: Meta-analysis: Are 3 Questions Enough to Detect Unhealthy Alcohol Use? Ann Intern Med 2008, 149(12):879-888.

11. Gordon AJ, Maisto SA, McNeil M, Kraemer KL, Conigliaro RL, Kelley ME, Conigliaro J: Three questions can detect hazardous drinkers. J Fam Pract 2001, 50(4):313-320.

12. Gual A, Segura L, Contel M, Heather N, Colom J: Audit-3 and audit-4: effectiveness of two short forms of the alcohol use disorders identification test. Alcohol Alcohol 2002, 37(6):591-596.

13. Hodgson R, Alwyn $T$, John B, Thom B, Smith A: The FAST alcohol screening test. Alcohol Alcohol 2002, 37(1):61.

14. Bush K, Kivlahan DR, McDonell MB, Fihn SD, Bradley KA: The Ambulatory Care Quality Improvement Project: The AUDIT Alcohol Consumption
Questions (AUDIT-C): An Effective Brief Screening Test for Problem Drinking. Arch Intern Med 1998, 158(16):1789-1795.

15. Aertgeerts B, Buntinx F, Ansoms S, Fevery J: Screening properties of questionnaires and laboratory tests for the detection of alcohol abuse or dependence in a general practice population. Br J Gen Pract 2001, 51(464):206-217.

16. Bradley KA, Bush KR, Epler AJ, Dobie DJ, Davis TM, Sporleder JL, Maynard C, Burman ML, Kivlahan DR: Two brief alcohol-screening tests From the Alcohol Use Disorders Identification Test (AUDIT): validation in a female Veterans Affairs patient population. Arch Intern Med 2003, 163(7):821-829.

17. Meneses-Gaya C, Zuardi AW, Loureiro SR, Hallak JEC, Trzesniak C, De Azevedo Marques JM, Machado-de-Sousa JP, Chagas MHN, Souza RM, Crippa JAS: Is the Full Version of the AUDIT Really Necessary? Study of the Validity and Internal Construct of Its Abbreviated Versions. Alcohol Clin Exp Re 2010, 34(8):1417-1424.

18. Chung T, Colby SM, Barnett NP, Rohsenow DJ, Spirito A, Monti PM: Screening Adolescents for Problem Drinking: Performance of Brief Screens against DSM-IV Alcohol Diagnoses(*).(Statistical Data Included). J Stud Alcohol 2000, 61(4):579.

19. Dawson DA, Grant BF, Stinson FS, Zhou Y: Effectiveness of the Derived Alcohol Use Disorders Identification Test (AUDIT-C) in Screening for Alcohol Use Disorders and Risk Drinking in the US General Population. Alcohol Clin Exp Re 2005, 29(5):844-854.

20. Bradley KA, DeBenedetti AF, Volk RJ, Williams EC, Frank D, Kivlahan DR: AUDIT-C as a Brief Screen for Alcohol Misuse in Primary Care. Alcohol Clin Exp Re 2007, 31(7):1208-1217.

21. Kelly TM, Donovan JE, Chung T, Bukstein OG, Cornelius JR: Brief screens for detecting alcohol use disorder among 18-20 year old young adults in emergency departments: Comparing AUDIT-C, CRAFFT, RAPS4-QF, FAST, RUFT-Cut, and DSM-IV 2-Item Scale. Addict Behav 2009, 34(8):668-674.

22. Aertgeerts B, Buntinx F, Bande-Knops J, Vanderrneulen C, Roelants M, Ansoms S, Fevery J: The Value of CAGE, CUGE, and AUDIT in Screening for Alcohol Abuse and Dependence Among College Freshmen. Alcohol Clin Exp Re 2000, 24(1):53-57.

23. Demartini K, Carey K: Correlates of AUDIT risk status for male and female college students. J Am Coll Health 2009, 58(3):233-239.

24. Fleming MF, Barry KL, Macdonald R: The Alcohol Use Disorders Identification Test (AUDIT) in a College Sample. Subst Use Misuse 1991, 26(11):1173-1185

25. Demartini KS, Carey KB: Optimizing the use of the AUDIT for alcohol screening in college students. Psychol Assess 2012, 24(4):954-963.

26. Dawson DA, Pulay AJ, Grant BF: A comparison of two single-item screeners for hazardous drinking and alcohol use disorder. Alcohol Clin Exp Res 2010, 34(2):364-374.

27. Lim MSC, Hellard ME, Aitken CK, Hocking JS: Surveillance of STI risk behaviour among young people attending a music festival in Australia, 2005-08. Aust N Z J Public Health 2009, 33:482-484.

28. Lim MSC, Hellard ME, Hocking JS, Spelman TD, Aitken CK: Surveillance of drug use among young people attending a music festival in Australia, 2005-2008. Drug Alcohol Rev 2010, 29(2):150-156.

29. Lim MSC, Hellard ME, Aitken CK, Hocking JS: Sexual-risk behaviour, selfperceived risk and knowledge of sexually transmissible infections among young Australians attending a music festival. Sex Health 2007 4(1):51-56.

30. Patrick D, Andrew M: Safe, familiar but big crowd still enjoys rocking day out 1st edition. Melbourne, Australia: The Age; 2010:5.

31. Bowring AL, Gold J, Dietze P, Gouillou M, Van Gemert C, Hellard ME: Know your limits: Awareness of the 2009 Australian alcohol guidelines among young people. Drug Alcohol Rev 2012, 31(2):213-223.

32. StataCorp: Stata Statistical Software: Release 11. College Station, TX: StataCorp LP; 2009

33. Chikritzhs TN, Pascal R: Trends in Youth Alcohol Consumption and Related Harms in Australian Jurisdictions, 1990-2002, National Alcohol Indicators: Bulletin No 6. Perth, Australia: National Drug Research Institute; 2004

34. Australian Bureau of Statistics: Australian Standard Geographical Classification (ASGC) Remoteness Areas (cat. no. 1216.0). Canberra: Australian Bureau of Statistics; 2006

35. Bland JM, Altman DG: Statistics notes: Cronbach's alpha. BMJ 1997, 314(7080):572

36. Allen J: Assessing Alcohol Problems: A Guide for Clinicians and Researchers. In. Bethesda, MD: National Institute on Alcohol Abuse and Alcoholism; 1995 
37. McCambridge J, Thomas BA: Short forms of the AUDIT in a Web-based study of young drinkers. Drug Alcohol Rev 2009, 28(1):18-24.

38. Mundt MP, Zakletskaia LI: Brown DD. Fleming MF: Alcohol-induced memory blackouts as an indicator of injury risk among college drinkers. Inj Prev; 2011.

39. Lim MSC, Aitken C, Hocking J, Hellard M: Discrepancies between young people's self-reported sexual experience and their perceptions of 'normality'. Sex Health 2009, 6(2):171-172.

40. Lim MSC, Hellard ME, Hocking JS, Aitken CK: A cross-sectional survey of young people attending a music festival: associations between drug use and musical preference. Drug Alcohol Rev 2008, 27(4):439-441.

doi:10.1186/1471-2458-13-301

Cite this article as: Bowring et al: Comparing short versions of the

AUDIT in a community-based survey of young people. BMC Public Health 2013 13:301.

\section{Submit your next manuscript to BioMed Central and take full advantage of:}

- Convenient online submission

- Thorough peer review

- No space constraints or color figure charges

- Immediate publication on acceptance

- Inclusion in PubMed, CAS, Scopus and Google Scholar

- Research which is freely available for redistribution 